\section{Fresh air}

\section{L.J.F.(Jo) Hermans, Leiden University, The Netherlands}

W hether at home or in the office: we feel comfortable when the temperature is around $20^{\circ} \mathrm{C}$ and the humidity around $50 \%$. There's some interesting physics here, especially in wintertime, when we have to heat and - almost inevitably - to humidify the outside air. The humidity aspect is a trivial consequence of the steepness of the $\mathrm{H}_{2} \mathrm{O}$ vapour pressure curve (see figure): at $0^{\circ} \mathrm{C}$ and $20^{\circ} \mathrm{C}$, we find 6 and 23 mbar, respectively, almost a factor of 4 difference. Therefore, when it freezes outside, the humidity cannot exceed some $25 \%$ inside, since the water content of the incoming air does not change by being heated. This is so unless we add water to the room. The air conditioning industry does that routinely in our labs and offices.

How hard is it to humidify the air in our home? In the stationary state this depends, of course, on the degree of ventilation. For a back-of-an-envelope calculation we use the rule of thumb that, for simple liquids including water, there is a factor of 1000 between the density of the liquid and that of the vapour if assumed at standard temperature and pressure. A litre of water, therefore, gives roughly $1 \mathrm{~m}^{3}$ of vapour if it were at 1 bar (it gives $1,244 \mathrm{~m}^{3}$ at STP, to be precise). Using the above $23 \mathrm{mbar}$ at $20^{\circ} \mathrm{C}$ we find, for a room of $100 \mathrm{~m}^{3}$ volume, that it takes about 1 litre to increase the humidity by $50 \%$ for a single load of air. If we assume a refreshment rate of once every hour, we see that humidification is effective only if we are prepared to pour a lot of water into our home daily. Or we have to minimize ventilation.

But ventilation is a must, if we don't want to run into health problems. In this context, an interesting physics aspect comes up. Suppose we instantaneously replace the air in our living room by cold outside air while keeping the heating off. Will the room be much colder after we wait for the new equilibrium to be reached? The answer is: very little, and it is easy to se why. It's all a matter of heat capacities, of course. But there are wooden furniture, brick

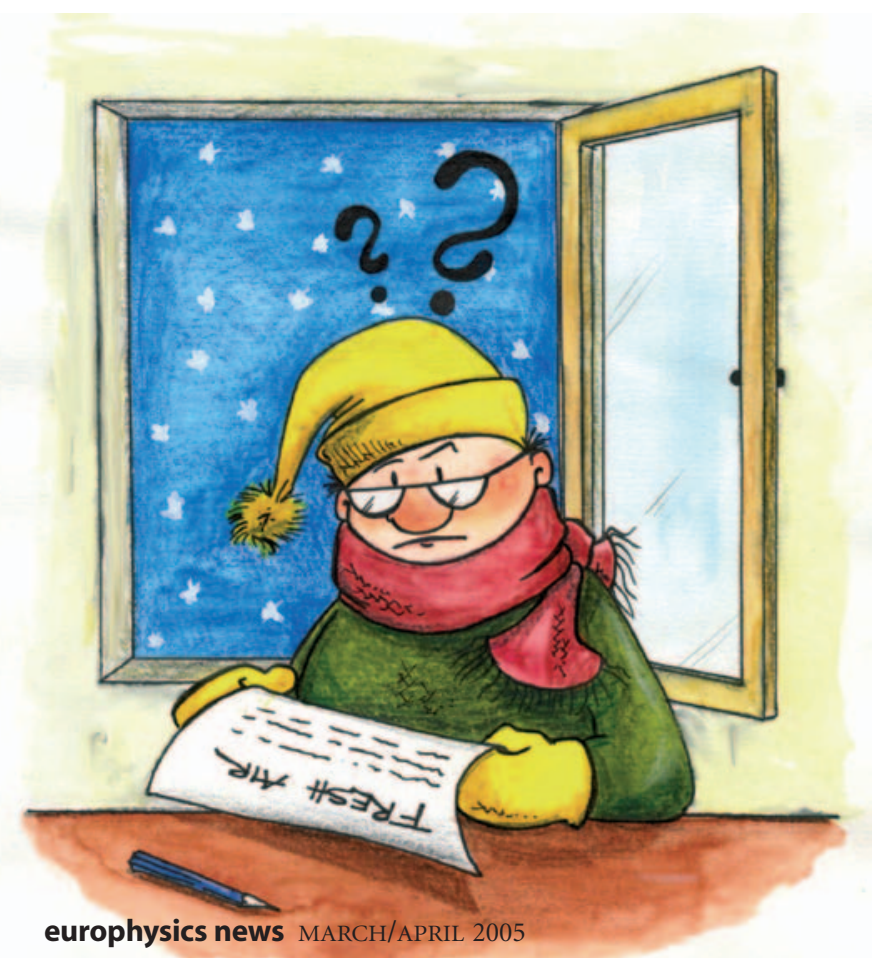

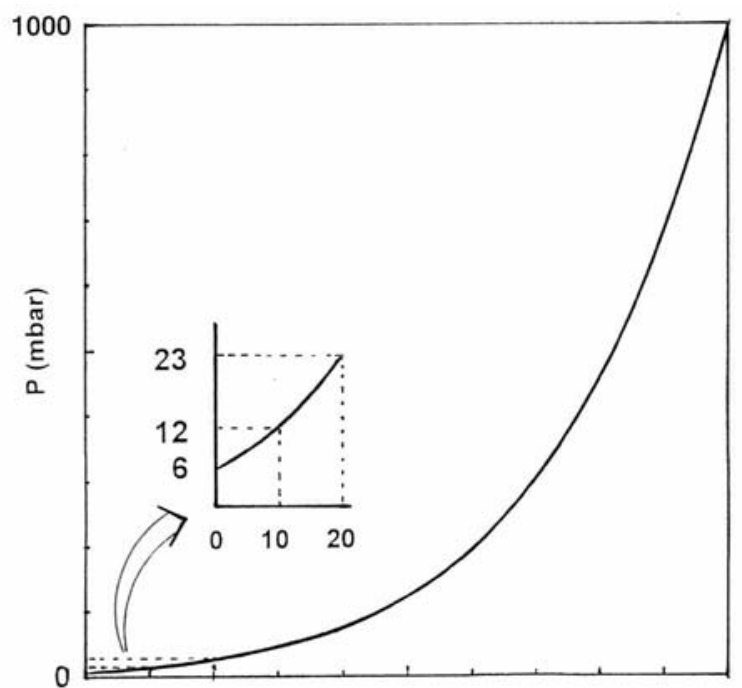

0

$100^{\circ} \mathrm{C}$

$\Delta$ Fig. 1: The vapour pressure of water, with an expansion of the 0 to $20^{\circ} \mathrm{C}$ temperature interval

walls, glass, metals, etc. in the room, which seems to make an estimate pretty hopeless. However, if we are only interested in an approximate value, there is an easy way out: If specific heats are taken not per mass but per volume, values for most solids and liquids are pretty much alike (around $2-3 \mathrm{~kJ} \cdot \mathrm{l}^{-1} \cdot \mathrm{K}^{-1}$ ). The reason is simple. We remember that atoms may differ enormously in mass, but they do not differ so much in 'size': the atomic number densities are rather equal. Moreover, the contribution of each atom to the specific heat is roughly the same (around $3 \mathrm{k}$, where $\mathrm{k}$ is the Boltzmann constant). For gases, of course, we have to take the above factor 1000 in the ratio of the densities into account.

Conclusion: when estimating heat capacities, a litre of liquid or solid and $\mathrm{a}^{3}$ of a gas at ambient temperature and pressure are pretty comparable.

So much for the 'rule of thumb'. We can return now to our room. It is clear that the volume of the 'solid' content of the room is far larger than $1 / 1000$ of the air, even if we are honest and count only half of the wall thickness. This shows that, indeed, the temperature of the room will be hardly affected by a single load of fresh air. This trivial exercise also suggests that opening the refrigerator for a second or so puts about as much heat into the refrigerator as leaving a tomato inside.

\section{About the author}

L.J.F. (Jo) Hermans recently retired as professor of Physics at Leiden University, The Netherlands. Main research topics: Internal-state-dependence of intermolecular and molecule-surface interactions, and nuclear spin conversion in polyatomic molecules. In the 1990s he served as a member of the EPS council. Presently he chairs the National Steering Committe for the World Year of Physics 2005.

\section{About the illustrator}

Wiebke Drenckhan (26) is currently doing her PhD in the "Physics of Foams" in Trinity College Dublin, Ireland. She has studied and worked in Germany, USA, New Zealand and France, being largely supported by the German National Merit Foundation. Additionally to taking a scientific approach to the world, she likes to capture its oddities in cartoons. 